\title{
Impact of Hypotension and Low Cerebral Perfusion Pressure on Outcomes in Children Treated with Hypothermia Therapy following Severe Traumatic Brain Injury: A post hoc Analysis of the Hypothermia Pediatric Head Injury Trial
}

\author{
James S. Hutchison ${ }^{a-c}$ Helena Frndova ${ }^{a}$ Tsz-Yan M. Lo ${ }^{a}$ b \\ Anne-Marie Guerguerian ${ }^{a-c}$ for the Hypothermia Pediatric Head Injury Trial \\ Investigators and the Canadian Critical Care Trials Group \\ a Departments of Critical Care and Pediatrics, Hospital for Sick Children, ${ }^{b}$ Neuroscience and Mental Health Research \\ Program, Hospital for Sick Children Research Institute, and ' Institute of Medical Science, University of Toronto, \\ Toronto, Ont., Canada
}

\section{Key Words}

Cerebral perfusion pressure $\cdot$ Children $\cdot$ Hypotension •

Hypothermia therapy · Traumatic brain injury

\begin{abstract}
Hypotension and low cerebral perfusion pressure are known to be associated with unfavorable outcome in children and adults with traumatic brain injury. Using the database from a previously published, randomized controlled trial of $24 \mathrm{~h}$ of hypothermia therapy in children with severe traumatic brain injury, we compared the number of patients with hypotension or low cerebral perfusion pressure between the hypothermia therapy and normothermia groups. We also determined the association between these physiologic insults and unfavorable outcome using regression analysis. There were more patients with episodes of hypotension or low cerebral perfusion pressure in the hypothermia therapy group than in the normothermia group. These physiologic insults were associated with unfavorable outcome in both
\end{abstract}

\section{KARGER}

Fax +4161306 1234

E-Mail karger@karger.ch

www.karger.com
(C) 2011 S. Karger AG, Basel

0378-5866/10/0326-0406\$38.00/0

Accessible online at:

www.karger.com/dne intervention groups. Hypotension and low cerebral perfusion pressure should be anticipated and prevented in future trials of hypothermia therapy in patients with traumatic brain injury.

Copyright $\odot 2011$ S. Karger AG, Basel

\section{Introduction}

Hypotension and low cerebral perfusion pressure are associated with mortality and morbidity in both adults $[1,2]$ and children [2-4] with traumatic brain injury. Hypothermia therapy is being used in patients with traumatic brain injury to control intracranial hypertension and as a neuroprotective therapy. However, the use of hy-

The investigators who participated in the study are listed in the appendix. 
pothermia therapy is associated with hypotension, as was noted in the largest study of hypothermia therapy, in adults with severe traumatic brain injury [5]. This raises concerns that hypothermia therapy may lead to secondary physiologic insults due to hypotension and low cerebral perfusion pressure.

We recently published a multicenter randomized controlled trial of hypothermia therapy in 225 children with severe traumatic brain injury in which hypothermia therapy was associated with a nonsignificant trend towards higher mortality [6]. Hypothermic patients also had a higher risk of hypotension and a significant risk of rebound intracranial hypertension during rewarming [6].

We hypothesized that hypotension and low cerebral perfusion pressure, which occurred during hypothermia therapy and rewarming, would be associated with, and explain part of, the worse outcome. To evaluate this hypothesis, we conducted a post hoc analysis on data from the Hypothermia Pediatric Head Injury Trial to examine the relationships between hypotension, low cerebral perfusion pressure and poor outcome.

\section{Methods}

The Hypothermia Pediatric Head Injury Trial was a randomized controlled trial of $24 \mathrm{~h}$ of hypothermia therapy in children with severe traumatic brain injury [6]. The trial was conducted at 17 centers in 3 countries. The eligibility criteria have previously been published [6]. The study was approved by the research ethics board of each participating institution. Written informed consent was obtained from the parents or guardians; deferred consent was obtained when parents or guardians were not available within $8 \mathrm{~h}$ after injury [7]. The patients were randomly assigned to a treatment group with the use of a central telephone-based system.

Patients were cooled with the use of surface cooling techniques. Following cooling we aimed to maintain the patients' esophageal temperature between 32 and $33^{\circ} \mathrm{C}$ for $24 \mathrm{~h}$, and to then rewarm at a rate of $0.5^{\circ} \mathrm{C}$ every $2 \mathrm{~h}$. After rewarming in the hypothermia group, and beginning immediately in the normothermia group, we aimed to keep the patients' esophageal temperature between 36.5 and $37.5^{\circ} \mathrm{C}$ until intracranial hypertension resolved. Guidelines for the management of intracranial pressure and cerebral perfusion pressure were established by consensus of the participating investigators after systematic reviews of the relevant evidence [8]. Patients were given $100 \%$ maintenance fluids. Patients who developed hypotension were treated with intravenous fluid boluses and inotropes.

The primary outcome for the study was the proportion of patients who had an unfavorable outcome - defined as severe disability, a persistent vegetative state or death - on the Pediatric Cerebral Performance Category scale at 6 months, which was assessed without knowledge of the treatment assignments. A trained site psychologist assessed each patient according to the 6-point
Pediatric Cerebral Performance Category scale (with a score of 1 representing normal performance, 2 mild disability, 3 moderate disability, 4 severe disability, 5 a persistent vegetative state, and 6 death) $[9,10]$. Blood pressure, intracranial pressure and cerebral perfusion pressure were recorded as the value measured closest to the 4 -hour time point in the case report form every $4 \mathrm{~h}$ for the first $72 \mathrm{~h}$, and then on a daily basis. Cointerventions and the rates of adverse events, including hypotension, were also recorded.

\section{Definitions of Hypotension}

For the purpose of our analysis, hypotension was defined as a systolic blood pressure of less than the fifth percentile according to the American Heart Association Pediatric Advanced Life Support guidelines: less than $90 \mathrm{~mm} \mathrm{Hg}$ for an age higher than or equal to 10 years, or a systolic blood pressure of less than $70 \mathrm{~mm}$ $\mathrm{Hg}$ plus the age (in years) multiplied by 2 for an age of $1-10$ years [11]. The same definition of hypotension was used in our primary analysis of data in the Hypothermia Pediatric Head Injury Trial [6]. We repeated the analysis using another definition of hypotension, which was a mean arterial pressure less than the fifth percentile: less than $1.5 \times$ age (in years) $+40 \mathrm{~mm} \mathrm{Hg}$ [12].

\section{Definition of Low Cerebral Perfusion Pressure}

A low cerebral perfusion pressure was defined as less than 50 $\mathrm{mm} \mathrm{Hg}$ for patients more than or equal to 10 years of age, and less than $40 \mathrm{~mm} \mathrm{Hg}$ for patients less than 10 years of age. This conservative definition of low cerebral perfusion pressure was modified from the published guidelines for the management of severe traumatic brain injury in infants, children and adolescents. In these guidelines, a threshold of $40 \mathrm{~mm} \mathrm{Hg}$ was considered a treatment guideline for children, and a cerebral perfusion pressure between 40 and $65 \mathrm{~mm} \mathrm{Hg}$ was considered a treatment option as an agerelated continuum [13].

\section{Statistical Analysis}

The numbers of patients with 1 or more episodes of hypotension or low cerebral perfusion pressure were compared between groups from 0 to $24 \mathrm{~h}$ and 25 to $72 \mathrm{~h}$ using a $\chi^{2}$ test. These were the time intervals used for analysis of physiologic variables in the primary publication from the Hypothermia Pediatric Head Injury Trial [6]. Blood pressure and cerebral perfusion pressure were compared between the hypothermia therapy and normothermia groups over time, using a general linear model with multiple comparisons using Tukey's test. The relationship between physiologic insults (episodes of hypotension or low cerebral perfusion pressure) and unfavorable outcome (Pediatric Cerebral Performance Category score of 4-6 at 6 months after injury), over the first 3 days ( $0-72 \mathrm{~h}$ ), from 0 to $24 \mathrm{~h}$ and from 25 to $72 \mathrm{~h}$, was determined using a binary regression analysis model with the Fisher scoring optimization technique.

\section{Results}

In all, 225 patients with severe traumatic brain injury were enrolled in the trial. Of these, 108 patients were randomized to hypothermia therapy and 117 patients were randomized to normothermia. The baseline characteris- 


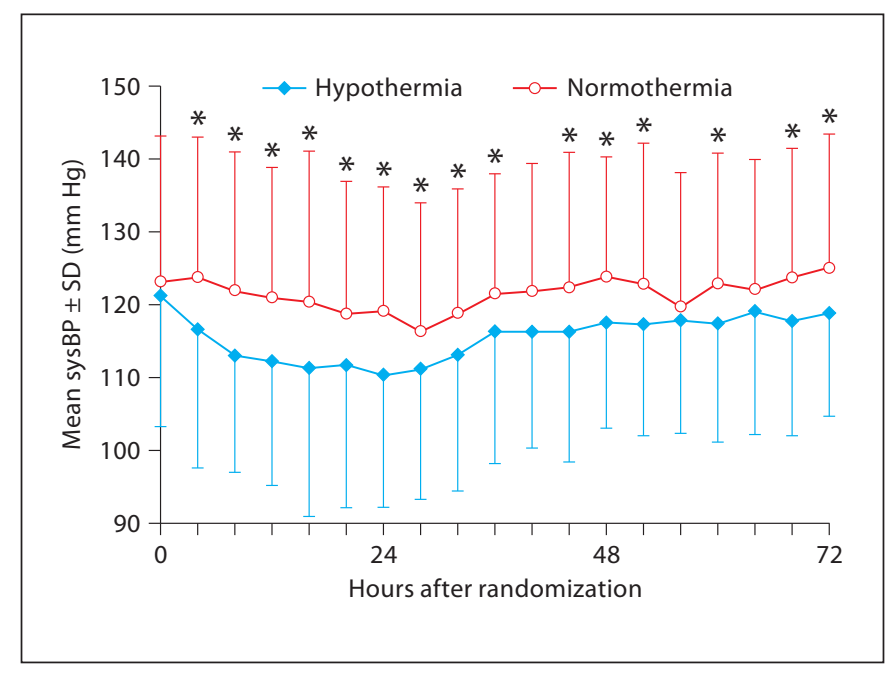

Fig. 1. Systolic blood pressure (sysBP) by groups. The figure shows sysBP as mean - SD in the hypothermia therapy group, and as mean + SD in the normothermia group. sysBP was compared between groups using a general linear model (see Methods section for the details). ${ }^{*} \mathrm{p}<0.05$.

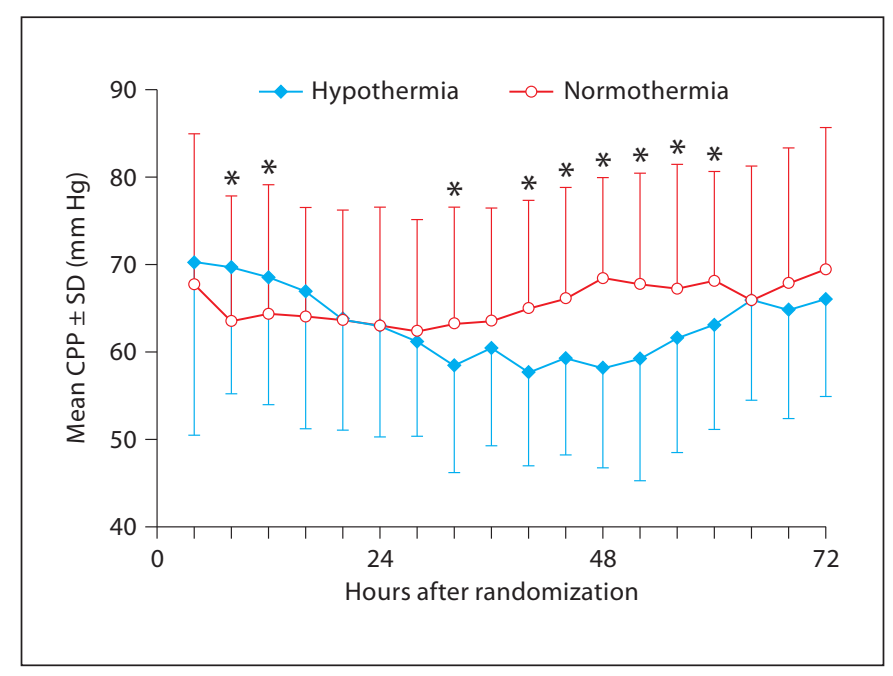

Fig. 3. Cerebral perfusion pressure (CPP) by groups. The figure shows CPP as mean - SD in the hypothermia therapy group, and as mean $+\mathrm{SD}$ in the normothermia group. CPP was compared between groups using a general linear model (see Methods section for the details). ${ }^{*} \mathrm{p}<0.05$.

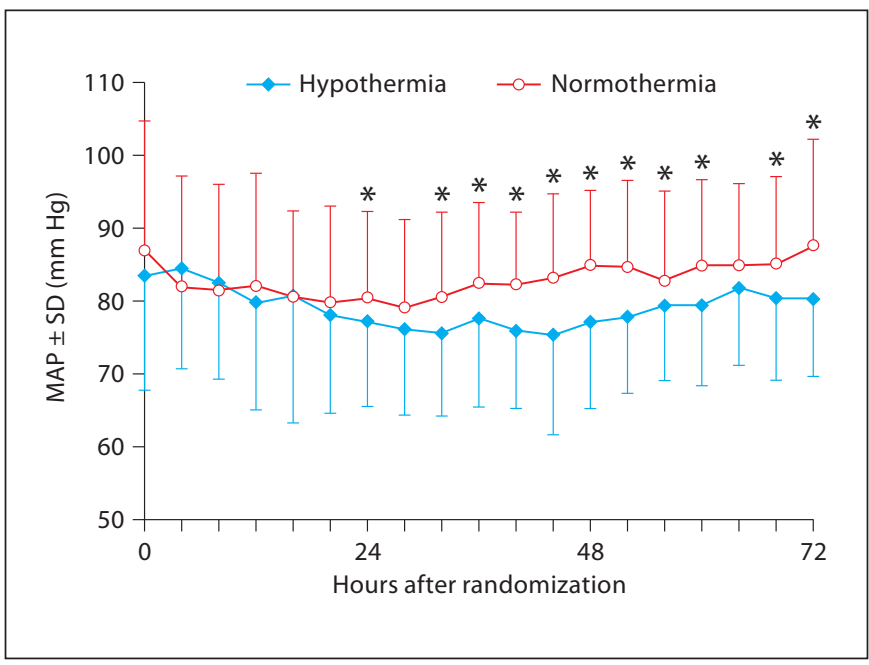

Fig. 2. Mean arterial pressure (MAP) by groups. The figure shows MAP as mean - SD in the hypothermia therapy group, and as mean + SD in the normothermia group. MAP was compared between groups using a general linear model (see Methods section for the details). ${ }^{*} \mathrm{p}<0.05$.

tics, injury severities and cointerventions in the hypothermia therapy and normothermia groups are presented in tables 1 and 2 of the primary publication of the Hypothermia Pediatric Head Injury Trial [6]. Twenty of the 225 patients (9\%) were lost to follow-up at 6 months -6 of 108 patients (6\%) in the hypothermia group, and 14 of 117 (12\%) in the normothermia group.

The hypothermia therapy group had a lower systolic blood pressure from 4 to $72 \mathrm{~h}$ (fig. 1) and a lower mean arterial pressure from 24 to $72 \mathrm{~h}$ (fig. 2), and there were more patients with 1 or more episodes of hypotension (low systolic pressure) in the hypothermia therapy group than in the normothermia group (table 1). There was no significant difference in the number of patients with 1 or more episodes of low mean arterial pressure in the hypothermia therapy group compared to the normothermia group (table 1). The hypothermia therapy group had a significantly higher cerebral perfusion pressure at 8 and $12 \mathrm{~h}$, and a significantly lower cerebral perfusion pressure from 32 to $60 \mathrm{~h}$ after injury, compared to the normothermia group (fig. 3). There were more patients with 1 or more episodes of low cerebral perfusion pressure in the hypothermia therapy group than in the normothermia group from 25 to $72 \mathrm{~h}$ but not from 0 to $24 \mathrm{~h}$ (table 1 ).

The results of the logistic regression analysis of the relationship between patients with 1 or more episodes of 
Table 1. Number of patients with 1 or more episodes of hypotension or low cerebral perfusion pressure

\begin{tabular}{|c|c|c|c|}
\hline Time after injury & $\begin{array}{l}\text { Hypothermia } \\
\text { therapy }(n=108)\end{array}$ & $\begin{array}{l}\text { Normothermia } \\
(\mathrm{n}=117)\end{array}$ & $\mathrm{p}$ \\
\hline \multicolumn{4}{|c|}{ Hypotension - low systolic blood pressure } \\
\hline $0-24 \mathrm{~h}$ & $26(24)$ & $15(13)$ & 0.03 \\
\hline $25-72 \mathrm{~h}$ & $49(45)$ & $38(32)$ & 0.047 \\
\hline \multicolumn{4}{|c|}{ Hypotension - low mean arterial pressure } \\
\hline $0-24 \mathrm{~h}$ & $23(21)$ & $30(26)$ & 0.44 \\
\hline $25-72 \mathrm{~h}$ & $47(44)$ & $43(37)$ & 0.30 \\
\hline \multicolumn{4}{|c|}{ Low cerebral perfusion pressure } \\
\hline $0-24 \mathrm{~h}$ & $37(34)$ & $45(38)$ & 0.51 \\
\hline $25-72 \mathrm{~h}$ & $73(68)$ & $61(52)$ & 0.02 \\
\hline
\end{tabular}

Data are shown as numbers with percentages in parentheses.

Table 2. Association between acute physiologic insult and unfavorable outcome in children following severe traumatic brain injury

\begin{tabular}{|c|c|c|c|c|c|c|}
\hline \multirow[t]{2}{*}{ Time after injury } & \multicolumn{3}{|c|}{ Hypothermia therapy } & \multicolumn{3}{|c|}{ Normothermia } \\
\hline & odds ratio & $95 \%$ CI & $\mathrm{p}$ & odds ratio & $95 \%$ CI & $\mathrm{p}$ \\
\hline \multicolumn{7}{|c|}{ Hypotension - low systolic pressure } \\
\hline $0-24 \mathrm{~h}$ & 1.25 & $0.86-1.83$ & 0.24 & 3.76 & $1.29-11.01$ & 0.02 \\
\hline $25-72 \mathrm{~h}$ & 1.13 & $1.00-1.27$ & 0.04 & 1.69 & $1.03-2.76$ & 0.04 \\
\hline $0-72 \mathrm{~h}$ & 1.11 & $1.00-1.23$ & 0.04 & 1.18 & $1.02-1.37$ & 0.03 \\
\hline \multicolumn{7}{|c|}{ Hypotension - low mean arterial pressure } \\
\hline $0-24 \mathrm{~h}$ & 1.18 & $0.81-1.74$ & 0.39 & 2.20 & $1.32-3.68$ & 0.003 \\
\hline $25-72 \mathrm{~h}$ & 1.10 & $0.98-1.23$ & 0.12 & 1.14 & $0.97-1.33$ & 0.10 \\
\hline $0-72 \mathrm{~h}$ & 1.08 & $0.98-1.20$ & 0.12 & 1.18 & $1.02-1.36$ & 0.02 \\
\hline \multicolumn{7}{|c|}{ Low cerebral perfusion pressure } \\
\hline $0-24 \mathrm{~h}$ & 1.08 & $0.83-1.42$ & 0.57 & 1.37 & $1.00-1.86$ & 0.05 \\
\hline $25-72 \mathrm{~h}$ & 1.13 & $1.02-1.26$ & 0.03 & 1.16 & $1.02-1.32$ & 0.03 \\
\hline $0-72 \mathrm{~h}$ & 1.09 & $1.00-1.19$ & 0.05 & 1.13 & $1.02-1.26$ & 0.02 \\
\hline
\end{tabular}

Regression analysis was used to determine the association between a physiologic insult (hypotension or low cerebral perfusion pressure) in the first 3 days after injury and unfavorable outcome (Pediatric Cerebral Performance Category score of 4-6) at 6 months after injury.

hypotension or low cerebral perfusion pressure and unfavorable outcome are shown in table 2. For patients in the hypothermia therapy group there was a significant association between 1 or more episodes of hypotension (low systolic pressure) and unfavorable outcome from 25 to $72 \mathrm{~h}(\mathrm{p}=0.04)$, but not from 0 to $24 \mathrm{~h}$ after injury ( $\mathrm{p}=$ $0.24)$. There was no significant association between low mean arterial pressure and unfavorable outcome in the hypothermia therapy group. There was a significant association between 1 or more episodes of low cerebral per- fusion pressure and unfavorable outcome from 25 to $72 \mathrm{~h}$ $(\mathrm{p}=0.03)$ but not from 0 to $24 \mathrm{~h}(\mathrm{p}=0.57)$. For patients in the normothermia group there was a significant association of both hypotension (low systolic pressure) and low cerebral perfusion pressure with unfavorable outcome during both time intervals (0-24 h and 25-72 h). There was a significant association between low mean arterial pressure and unfavorable outcome from 0 to $24 \mathrm{~h}$ $(\mathrm{p}=0.003)$ but not from 25 to $72 \mathrm{~h}(\mathrm{p}=0.10)$ in the normothermia group. 


\section{Discussion}

We found that there were more episodes of hypotension and low cerebral perfusion pressure in the hypothermia therapy group than in the normothermia group in a multicenter randomized controlled trial of $24 \mathrm{~h}$ of hypothermia therapy in children with severe traumatic brain injury. Hypothermia therapy resulted in more frequent hypotension (low systolic blood pressure) during all study periods, and in lower cerebral perfusion pressure in the 25 - to 72-hour time period. Low cerebral perfusion pressure was slightly (nonsignificantly) less frequent in the hypothermia group in the 0 - to 24 -hour time period, likely due to a more pronounced effect of hypothermia therapy on intracranial pressure than on mean arterial pressure during that time period. We have additionally demonstrated that hypotension and low cerebral perfusion pressure were significantly associated with unfavorable outcome in both intervention groups.

In previous studies of both adults and children with traumatic brain injury, hypotension was associated with a higher mortality and worse neurological outcome among survivors $[1,3,4,14]$. Clifton and colleagues also reported significantly more frequent episodes of hypotension during treatment with hypothermia therapy in adults with severe traumatic brain injury [5]. However, hypotension was not reported in previous trials of hypothermia therapy in children with severe traumatic brain injury $[15,16]$. During rewarming following hypothermia therapy, an increase in cerebral blood flow can lead to intracranial hypertension and vasodilatation can result in hypotension. Untreated rises in intracranial pressure, falls in blood pressure, or both will cause a reduction in cerebral perfusion pressure. Low cerebral perfusion pressure is also associated with unfavorable outcome in children with traumatic brain injury $[17,18]$. We hypothesize that the episodes of hypotension and low cerebral perfusion pressure led to a higher risk of unfavorable outcome in patients treated with hypothermia therapy in our trial. Although a statistical association of episodes of hypotension and low cerebral perfusion pressure with unfavorable outcome does not prove cause and effect, there is evidence from animal models that the brain is selectively vulnerable to hypotensive insults following trauma $[19,20]$. These physiologic insults do not damage a healthy brain but can lead to cell death in selectively vulnerable neurons following trauma [21]. We speculate that this phenomenon also leads to higher mortality and worse neurological outcome in humans with traumatic brain injury following hypotensive insults.
The time window in which the brain remains vulnerable to hypotensive insults is unknown following traumatic brain injury. This window is likely to vary from patient to patient and may be related to loss of autoregulation and vulnerability to cerebral ischemia following trauma [22]. Our patients were rewarmed following $24 \mathrm{~h}$ of hypothermia therapy [6]. It is likely that this was too early and that the brain remained particularly vulnerable to hypotension, intracranial hypertension and low cerebral perfusion pressure at this early time following the injury. The use of intravenous volume loading and inotropes and/or vasopressors to support blood pressure, aggressive management of rebound intracranial hypertension and a slower rate of rewarming than we used in the Hypothermia Pediatric Head Injury Trial might minimize the incidence of episodes of hypotension. The aim of this rewarming protocol should be to prevent hypotension, rebound intracranial hypertension and low cerebral perfusion pressure in future clinical trials. It should be noted, however, that episodes of hypotension and low cerebral perfusion pressure could not be completely prevented despite more extensive treatment protocols in the North American Brain Injury Study - Hypothermia II compared to study I by Clifton et al. [23].

Our study has a few limitations. We recorded blood pressure, intracranial pressure and cerebral perfusion pressure on the study case report form only every $4 \mathrm{~h}$ during the first $72 \mathrm{~h}$. Thus, the incidence of episodes of hypotension and low cerebral perfusion pressure was likely higher than we reported. Continuous recording of the depth and duration of episodes of hypotension and low cerebral perfusion pressure is more strongly associated with outcome than intermittent recording of blood pressure and cerebral perfusion pressure [17]. Continuous monitoring of the pressure reactivity index to detect loss of autoregulation and define optimal cerebral perfusion pressure targets may prevent secondary physiologic insults and improve outcome in future studies of children with severe traumatic brain injury [24].

In summary, our protocol of $24 \mathrm{~h}$ of hypothermia therapy and rewarming by $0.5^{\circ} \mathrm{C}$ every $2 \mathrm{~h}$ was associated with a higher risk of hypotension and low cerebral perfusion pressure. These physiologic insults were associated with unfavorable outcome at 6 months following injury. The short durations of hypothermia therapy in our study, and the relatively rapid rewarming period might be responsible for some of these episodes. Thus, management protocols that prevent hypotension and low cerebral perfusion pressure should be considered in future trials of hypothermia therapy. 


\section{Appendix}

List of Investigators

The following investigators participated in this study:

- Steering committee - J.S. Hutchison, R.E. Ward, J. Lacroix, P.C. Hébert, P.W. Skippen, M.A. Barnes, P.G. Meyer, K.P. Morris, H.M. Kirpalani, R.N. Singh, P.B. Dirks, D.J. Bohn, D. Moher

- Statisticians - I. Gaboury, N. Barrowman, D. Ferguson, S. Doucette (University of Ottawa, Ottawa, Ont., Canada)

- Data monitoring committee - A. Donner (University of Western Ontario, London, Ont., Canada), T. Klassen (University of Alberta, Edmonton, Alta., Canada), M. Lawson (University of Ottawa, Ottawa, Ont., Canada), J. Kestle (University of Utah, Salt Lake City, Utah, USA)

Institutions, Site Investigators, Neurosurgeons, Research Coordinators and Psychologists

The number of patients enrolled at each institution are shown in parentheses.

Canada. British Columbia Children's and Women's Hospital, Vancouver, B.C. (14): P. Skippen, D. Cochrane, M. Bailey, G. Krahn, M. McAllister; Stollery Children's Hospital, Edmonton, Alta. (15): A. Joffe, K. Aronyk, E. Kowal-Zuk, H. Richardson, A. Witol; Alberta Children's Hospital, Calgary, Alta. (6): R. Connors, M. Hamilton, L. Simonot, B. van Mastrigt; Royal University Hospital, Saskatoon, Sask. (7): G. Kasian, L. Givelichian, B. Rempel, J. Rozdilsky, J. Nanson; Children's Hospital of Winnipeg, Winnipeg, Man. (4): M. Kesselman, B.J. Hancock, D. Fewer, J. Binnun, A. Kipling, J. Bow, M. Teschuk; Children's Hospital of Western Ontario, London, Ont. (21): R. Singh, Y. Ouellette, A. Ranger, M.A. Linley, S. McKay, P. Frewen; Chedoke McMaster Hospital, Hamilton, Ont. (14): H. Kirpalani, K. Chong, S. Monkman, M. Kho, L. Tuff; Hospital for Sick Children, Toronto, Ont. (27): D. Bohn, J. Hutchison, P. Dirks, R. Gaitiero, K. McFarland, M. Barnes, R. Donnelly; Children's Hospital of Eastern Ontario, Ot- tawa, Ont. (24): D. Creery, E. Ventureyra, J. Sadler, K. Heddon, S. Kuehn, A. George; Montreal Children's Hospital, Montreal, Que. (5): R. Gottesman, S. Liben, J.-P. Farmer, E. DeConinck, B. Groleau, S. Daigneault; Sainte-Justine Hospital, Montreal, Que. (19): J. Lacroix, C. Farrell, J.-C. Marchal, C. Mercier, D. David, A. Proietti, A. Dufresne; IWK Health Centre, Halifax, N.S. (2): C. Soder, C. Donnelly, A. Nauffts, C. Whitelaw, J. Backman, H. Bawden, N. Ciccarelli.

England. Great Ormond Street Children's Hospital, London (22): D. Lutman, M. Kenny, D. Lees, L. McCormick, E. Sturgess, D. Darby, S. Cowlish, D. Hearst, M. Bryon; Southampton General Hospital, Southampton (2): S. Watkins, S. Cottrell, C. Boyles, F. Kirkham, J. Limond; Birmingham Children's Hospital, Birmingham (15): K. Morris, J. Grech, C. Naylor, J. Menzies, H. Baxter, V. Hacker, J. Houghton, A. Lawson; Royal Manchester Children's Hospital, Manchester (1): K. Hawkins, P. Langridge, V. McLaughlin, J. Woodward.

France. Groupe Hospitalier Necker-Enfants Malades, Paris (27): P. Meyer, C. Mouleres, A. Perroteau, A. Laurent-Vannier, P. Notteghem.

\section{Acknowledgments}

The Hypothermia Pediatric Head Injury Trial was funded by the Canadian Institutes of Health Research (Canadian Neurotrauma Research Program; MCT50398), the Ontario Neurotrauma Foundation (ONBO-00009 and ONRO-41), the Rick Hansen Institute, the Hospital for Sick Children Foundation (XG 99-057), the Physicians Services Incorporated (98-62), the Fonds de la Recherche en Santé du Quebec (004095-104), the Children's Hospital of Eastern Ontario Research Institute [98/16S(E)] and the Direction de la Recherche Clinique Assistance Publique Hôpitaux de Paris (P010208).

\section{References}

1 Chesnut RM, Marshall LF, Klauber MR, Blunt BA, Baldwin N, Eisenberg HM, et al: The role of secondary brain injury in determining outcome from severe head injury. J Trauma 1993;34:216-222.

-2 Chambers IR, Treadwell L, Mendelow AD: Determination of threshold levels of cerebral perfusion pressure and intracranial pressure in severe head injury by using receiver-operating characteristic curves: an observational study in 291 patients. J Neurosurg 2001;94: 412-416.

-3 Pigula FA, Wald SL, Shackford SR, Vane DW: The effect of hypotension and hypoxia on children with severe head injuries. J Pediatr Surg 1993;28:310-314.

4 Kokoska ER, Smith GS, Pittman T, Weber TR: Early hypotension worsens neurological outcome in pediatric patients with moderately severe head trauma. J Pediatr Surg 1998; 33:333-338

Hypotension and Low Cerebral Perfusion Pressure in Severe TBI
5 Clifton GL, Miller ER, Choi SC, Levin HS, McCauley S, Smith KR Jr, et al: Lack of effect of induction of hypothermia after acute brain injury. N Engl J Med 2001;344:556563.

6 Hutchison JS, Ward RE, Lacroix J, Hébert PC, Barnes MA, Bohn DJ, et al: Hypothermia therapy after traumatic brain injury in children. N Engl J Med 2008;358:2447-2456.

7 Abramson NS, Meisel A, Safar P: Deferred consent: a new approach for resuscitation research on comatose patients. JAMA 1986; 255:2466-2471.

8 Hutchison J, Ward R, Lacroix J, Hébert P, Skippen P, Barnes M, et al: Hypothermia Pediatric Head Injury Trial: the value of a pretrial clinical evaluation phase. Dev Neurosci 2006;28:291-301.
9 Fiser DH: Assessing the outcome of pediatric intensive care. J Pediatr 1992;121:68-74.

10 Fiser DH, Tilford JM, Roberson PK: Relationship of illness severity and length of stay to functional outcomes in the pediatric intensive care unit: a multi-institutional study. Crit Care Med 2000;28:1173-1179.

11 The International Liaison Committee on Resuscitation (ILCOR) consensus on science with treatment recommendations for pediatric and neonatal patients: pediatric basic and advanced life support. Pediatrics 2006; 117:e955-e977.

12 Haque IU, Zaritsky AL: Analysis of the evidence for the lower limit of systolic and mean arterial pressure in children. Pediatr Crit Care Med 2007;8:138-144. 
13 Adelson PD, Bratton SL, Carney NA, Chesnut RM, du Coudray HE, Goldstein B, et al: Guidelines for the acute medical management of severe traumatic brain injury in infants, children, and adolescents. Chapter 8. Cerebral perfusion pressure. Pediatr Crit Care Med 2003;4:S31-S33.

14 Chesnut RM: The management of severe traumatic brain injury. Emerg Med Clin North Am 1997;15:581-604.

-15 Biswas AK, Bruce DA, Sklar FH, Bokovoy JL, Sommerauer JF: Treatment of acute traumatic brain injury in children with moderate hypothermia improves intracranial hypertension. Crit Care Med 2002;30:2742-2751.

-16 Adelson PD, Ragheb J, Kanev P, Brockmeyer D, Beers SR, Brown SD, et al: Phase II clinical trial of moderate hypothermia after severe traumatic brain injury in children. Neurosurgery 2005;56:740-754.
17 Chambers IR, Jones PA, Lo TY, Forsyth RJ, Fulton B, Andrews PJ, et al: Critical thresholds of intracranial pressure and cerebral perfusion pressure related to age in paediatric head injury. J Neurol Neurosurg Psychiatry 2006;77:234-240.

18 Jones PA, Chambers IR, Lo TY, Andrews PJ, Chaudhry W, Clark A, et al: Quantification of secondary CPP insult severity in paediatric head injured patients using a pressuretime index. Acta Neurochir Suppl 2005;95: 29-32.

19 Ishige N, Pitts LH, Berry I, Nishimura MC, James TL: The effects of hypovolemic hypotension on high-energy phosphate metabolism of traumatized brain in rats. J Neurosurg 1988;68:129-136.

20 Clark RS, Kochanek PM, Dixon CE, Chen M, Marion DW, Heineman S, et al: Early neuropathologic effects of mild or moderate hypoxemia after controlled cortical impact injury in rats. J Neurotrauma 1997;14:179-189.
1 Mikrogianakis A, Shaye RE, Griffin P, Kawesa S, Lockwood J, Gendron NH, et al: Hypoxia alters the expression of inhibitor of apoptosis proteins after brain trauma in the mouse. J Neurotrauma 2007;24:338-353.

22 Chaiwat O, Sharma D, Udomphorn Y, Armstead WM, Vavilala MS: Cerebral hemodynamic predictors of poor 6-month Glasgow Outcome Score in severe pediatric traumatic brain injury. J Neurotrauma 2009;26:657663.

23 Clifton GL, Drever P, Valadka A, Zygun D, Okonkwo D: Multicenter trial of early hypothermia in severe brain injury. J Neurotrauma 2009;26:393-397.

24 Brady KM, Shaffner DH, Lee JK, Easley RB, Smielewski P, Czosnyka M, et al: Continuous monitoring of cerebrovascular pressure reactivity after traumatic brain injury in children. Pediatrics 2009;124:e1205-e1212. 